\title{
Evaluating the Dissemination Impact of Social Networks based on an Entropy and Analytic Hierarchy Process Hybrid Model
}

\author{
Qin Wang \\ College of Transport \& Communications, Shanghai \\ Maritime University \\ Sino-US Global Logistics Institute, Shanghai Jiao Tong \\ University \\ Shanghai, China
}

\author{
Xiao-li Wang \\ School of Management, Shanghai University of Engineering \\ Science \\ Shanghai, China
}

\author{
Zi-sheng Liu \\ College of Transport \& Communications, Shanghai \\ Maritime University \\ Shanghai, China
}

Jian Xue

College of Economics and Management, Shaanxi University of Science \&Technology

Xi'an, China

\begin{abstract}
Nowadays, social networks greatly affect people's daily life. However, the need to evaluate the dissemination impact of social networks based on multiple criteria has become a necessity. In this paper, the authors construct an evaluation index system, develop an entropy and Analytic Hierarchy Process hybrid model, and derive the priority among the alternative social networks, including Facebook, Twitter, Snapchat, Wechat and Sina Microblogging, based on the bybrid weight, which is determined by the entropy weight and Analytic Hierarchy Process weight. The results reveal that the impact of social networks is influenced by several key performance indicators, including the number of daily active users (DAU), the growth rate of DAU, the average number of messages released per day, net profit, and market value. The study shed some lights on multi-criteria decision making in social networks.
\end{abstract}

Keywords-dissemination impact; social networks; entropy weight; analytic hierarchy process

\section{INTRODUCTION}

Nowadays, social networks is widely used by global business managers, researchers and public policy makers to perceive instant online news and topics [1-2], make reinvestment decisions [3], share feelings and opinions [4], predict the propagation behavior [5]. In fact, social networks have both positive and negative influence on the vaccination behavior in homogeneous networks and heterogeneous networks, whether the behavior is promoted or reduced depends on the vaccination cost and network structure [6-7]. Chang et al [8] conducted an empirical study of Facebook and LinkedIn to show that social networking services (SNS) had positive and negative influence on people's feelings and opinions, the results also implied that user trust was an important performance factor to determine the propagation

\section{behavior of social network.}

Thus, many peers investigated various strategies to improve dissemination impact of social networks and retain online social network users. Schnitzler et al [9] studied how to enhance the research impact for researchers by using Twitter as an empirical study, the results indicated that Microblogging was considered as an effective channel to promote the research impact. Zhang et al [10] conducted a survey of Wechat and applied the structural equation modeling (SEM) method to investigate how to retain network users, and revealed that social value and hedonic value matters considerably in users' continuance intention. Mamonov and Benbunan [11] showed that the perceived social utility and convenience fostered the usage of social networks, while the perceived value and privacy concerns negatively affected the number of network users. Gan et al [12] emploied a nationwide survey of 2000 American citizens and found that several core factors affected the adoption of online social networks (OSN), including the age group, gender category, availability of mobile devices, they also revealed that online video viewing enhanced the usage proportion of OSN.

The analytic hierarchy process (AHP) is a powerful approach to solve the multi criteria decision problems [13-14]. However, number of peers combined the entropy method (EM) with AHP as to provide both qualitative and quantitative analysis of data collected from reports and interviewers. Chen et al [15] constructed an evaluation index system and provided a hybrid evaluation method using the EM and AHP to assess the safety grade of food product. Li et al [16] proposed a customer satisfaction evaluation method by combining the AHP and entropy method together in order to investigate the customer satisfaction value for new product. 
From above literatures, it is clear that social networks play an important role in our daily life, and it is essential to evaluate the impact of different social networks. However, the existing literature mainly focus on the evolution dynamic of social networks, such as the effect of network structure, spreading rate, remember rate and forgetting rate on the threshold of diffusion model [4-5]. Very limited studies investigate the dissemination grade of social networks. But this study constructs a new evaluation index system, which fully considers the core performance indicators such as the number of daily active users (DAU), the growth rate of DAU, the average number of messages released per day, net profit and market value. In addition, the authors develop a hybrid model to derive the influence grade of social networks by incorporating the entropy model into an AHP approach.

The rest of this paper is organized as follows: In Section 2, we provide the hierarchy structure of the evaluation model. In Section 3, we make a description of the evaluation index system (ie. the number of DAU, the growth rate of DAU, the average number of messages released per day, net profit and market value), develop the model of evaluating the dissemination impact of social networks (EDISN), and derive the hybrid weight and influence grade of five social networks based on the entropy weight and AHP weight. Finally, conclusions are drawn in Section 4.

\section{THE HIERARCHY STRUCTURE OF EDISN MODEL}

The dissemination impact of social networks is determined by several performance indicators. On the basis of data availability and reliability, considering the previous existing outcomes [17], five factors are selected for the hybrid model, including DAUs, DAUs' Growth, Average Daily Messages, Net Income and Market Value. The hierarchy structure of the hybrid model is shown in Fig. 1.

DAUs represents the number of daily active users and is the most important data in evaluating the impact of social networks. DAUs' Growth means the increase number of daily active users compared to the same quarter of last year, which represents the growth rate of social network users. Average Daily Messages represents the average number of messages released per day, including text, video and photos. Net Income is equal to the difference between total income and related tax. Market Value represents the true underlying value of each corporation of social networks.

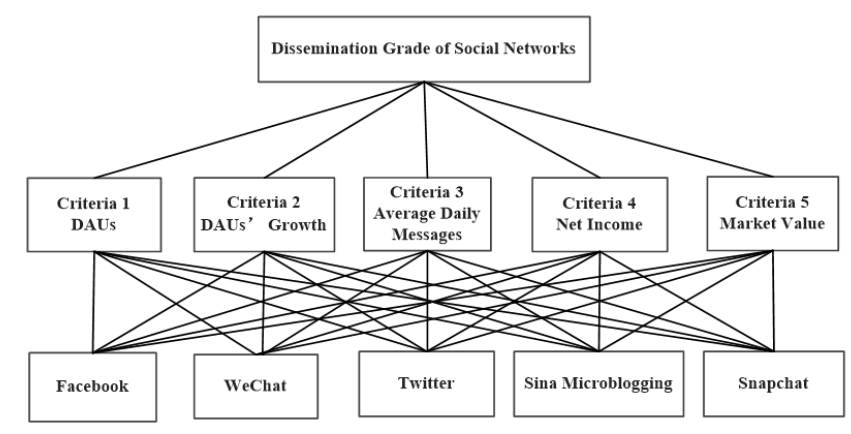

Fig. 1 The hierarchy structure of EDISN model

\section{MODEL DESCRIPTION}

\section{A. Entropy Weight Model}

The item "entropy" refers to the relative importance of factors that affect the dissemination of social networks [14]. Suppose the evaluation index system and the standardized matrix can be written as

$$
A=\left(a_{i j}\right), A=\left(\tilde{a}_{i j}\right), i=1, \ldots, m, j=1, \ldots, n .
$$

Then, entropy weight can be derived by two steps.

Step 1: The performance indicator values of five social networks were standardized by using (2), then we have

$$
a_{i j}=\frac{a_{i j}-\sigma_{j}}{\rho_{j}-\sigma_{j}},
$$

where, $a_{i j}$ is the standardized value, $\rho_{j}=\max \left\{a_{i j}\right\}$, $\sigma_{j}=\min \left\{a_{i j}\right\}, i=1, \ldots, m, j=1, \ldots, \mathrm{n}$.

Step 2: The entropy weight $X_{j}$ can be calculated by using (3) and (4), then we have

$$
\begin{gathered}
x_{j}=\frac{1-\mathrm{p}_{j}}{\sum_{j=1}^{n}\left(1-\mathrm{p}_{j}\right)}, j=1, \ldots, n . \\
p_{j}=-\left(\frac{1}{\ln (\mathrm{m})}\right) \sum_{j=1}^{n}\left(a_{i j} \ln \left(a_{i j}\right)\right), j=1, \ldots, n .
\end{gathered}
$$

\section{B. Analytic Hierarchy Process Model}

Suppose $B$ denotes the decision matrix of the five performance indicators, the value of which represents the relative importance of indicators. Twenty experts were interviewed to assign the value of the decision matrix.

$$
B=\left(b_{i j}\right), i=1, \ldots, m, j=1, \ldots, n
$$

The AHP weight can be derived by three steps.

Step 1: The decision matrix can be normalized as follows

$$
\begin{gathered}
B=\left(b_{i j}\right), i, j=1, \ldots, m . \\
b_{i j}=\frac{b_{i j}}{\sum_{i=1}^{m} b_{i j}}
\end{gathered}
$$

Step 2: The AHP weight can be calculated by using (8)

$$
y_{j}=\frac{\sum_{j=1}^{m} b_{i j}}{m},
$$

Step 3: The Consistency ratio CR is calculated to examine the consistency of the standardized weights, and CR can be 
computed by $C R=\frac{C I}{R I}$, where $C I=\frac{\lambda_{\max }-m}{m-1}$, $\lambda_{\max }=\sum_{i=1}^{m} \frac{(B Y)_{i}}{m y_{i}}$.

\section{The Hybrid Evaluation Model}

The hybrid model implemented minimizes the error between the entropy weight and AHP weight. Suppose $\omega_{j}$ represents the hybrid weight, the we have

$$
\begin{aligned}
\omega_{j} & =\mu x_{j}+(1-\mu) \mathrm{y}_{j} \\
\text { Min } e & =\sum_{j=1}^{m}\left[\left(\omega_{j}-x_{j}\right)^{2}+\left(\omega_{j}-y_{j}\right)^{2}\right] .
\end{aligned}
$$

The final total grades of alternatives were computed by $G_{j}=\sum_{j=1}^{m} \omega_{j} \tilde{a}_{i j}$, where $\tilde{a}_{i j}$ represents the standardized matrix of the performance indicators that can be easily collected from statistics institute.

\section{RESULTS AND DISCUSSION}

Five social networks were evaluated by the entropy and AHP hybrid model. The data of the five networks based on five criteria were shown in Table 1. The data of DAUs and DAUs' Growth were collected from Financial Reports of Facebook, Tencent, Twitter, Sina, Snapchat, WeChat public account and Sina website in the 3rd and 4th Quarter of 2016. The data of Average Daily Messages were collected from"Wechat User Global Report 2016", Royal Pingdom website and WeChat platform. Net Income data were collected from Financial Reports of Facebook, Tencent, Twitter, Sina, and Snapchat in 2016. The Market value data were collected from Sohu website in 1st Quarter of 2017.

The final hybrid weight is calculated by four steps.

Step 1. The performance indicator values of five social networks were standardized

$$
A=\left(\tilde{a}_{i j}\right)=\left(\begin{array}{ccccc}
1 & 0.9357 & 1 & 1 & 1 \\
0.5765 & 1 & 0.0001 & 0.2993 & 0.0005 \\
0.0247 & 0 & 0.0069 & 0.0858 & 0 \\
0 & 0.0234 & 0 & 0.0581 & 0.0004 \\
0.0174 & 0.1345 & 0.5263 & 0 & 0.0610
\end{array}\right) .
$$

Step 2. The entropy weight $X_{j}$ can be calculated as follows

$$
x_{j}=(0.1928,0.2030,0.2110,0.1489,0.2443)
$$

Step 3. The decision matrix is shown in matrix $B$, and the AHP weight $y_{j}$ is computed as follows

$$
B\left(\begin{array}{ccccc}
1 & 5 & 3 & 0.3333 & 0.2 \\
0.2 & 1 & 0.5 & 0.1429 & 0.1111 \\
0.3333 & 2 & 1 & 0.2 & 0.1429 \\
3 & 7 & 5 & 1 & 0.3333 \\
5 & 9 & 7 & 3 & 1
\end{array}\right)
$$$$
y_{j}=(0.1356,0.0371,0.0603,0.2619,0.5050)
$$

TABLE I INFORMATION ABOUT FIVE SOCIAL NETWORKS

\begin{tabular}{|c|c|c|l|l|l|}
\hline & DAUs & $\begin{array}{l}\text { DAUs' } \\
\text { Growth }\end{array}$ & $\begin{array}{l}\text { Average } \\
\text { Daily } \\
\text { Messages }\end{array}$ & $\begin{array}{l}\text { Net } \\
\text { Income }\end{array}$ & $\begin{array}{l}\text { Market } \\
\text { Value }\end{array}$ \\
\hline Facebook & 12.3 & 1.88 & 475000 & 102.17 & 3941.6 \\
\hline WeChat & 7.68 & 1.99 & 70 & 26.97 & 113.7 \\
\hline Twitter & 1.66 & 0.28 & 3300 & 4.06 & 111.7 \\
\hline $\begin{array}{c}\text { Sina } \\
\text { Micro- } \\
\text { blogging }\end{array}$ & 1.39 & 0.32 & 13 & 1.08 & 113.4 \\
\hline Snapchat & 1.58 & 0.51 & 250000 & -5.15 & 345.4 \\
\hline
\end{tabular}

Step 4. The value of Consistence Index, Random Consistence Index and Consistence Ratio were calculated and shown as follows

$$
C I=0.0467, R I=1.12, C R=0.0417 .
$$

Noting that the value of Consistence Ratio is less than $10 \%$, which indicates that the AHP weight is consistent.

Thus, the hybrid weight $\omega_{j}$, the final total grades of the five networks $g_{j}$ were derived

$$
\begin{gathered}
\omega_{j}=(0.1642,0.1201,0.1356,0.2054,0.3746) \\
g_{j}=(0.99,0.28,0.02,0.01,0.11)
\end{gathered}
$$

It is concluded that Facebook is the most influential social network, Wechat and Snapchat follow the second place, Twitter and Sina Microblogging have weak influence on peolple's life as the Twitter has declined rapidly and Sina Microblogging has limited social network users.

To investigate the dissemination influence of social networks, we have presented a hybrid evaluation model based on five criteria. In addition, we have performed a case study of five alternative social networks, the data of which could be easily collected from official department. The evaluation model leverages the advantage of both qualitative and quantitative analysis of data from expert investigation and financial report of each corporation. The results could provide suggestions for policy makers in information dissemination.

\section{ACKNOWLEDGEMENTS}

This study was supported by grants from the Shanghai Pujiang Program (No.14PJC060), the National Natural Science Youth Foundation of China (No. 71503163), the National Social Science Foundation of China (No. 16BGL146) and Philosophy Social Science Youth Foundation of Shanghai (No. 2015EGL007). 


\section{REFERENCES}

[1] A. M. Aladwani. Facilitators, characteristics, and impacts of Twitter use: Theoretical analysis and empirical illustration [J]. International Journal of Information Management, 2015, 35(1): 15-25.

[2] J. Bernabé-Moreno, A. Tejeda-Lorente, C. Porcel, et al. A new model to quantify the impact of a topic in a location over time with Social Media [J]. Expert Systems with Applications, 2015, 42(7): 3381-3395.

[3] P. Fu, A. Zhu, H. Ni, et al. Threshold behaviors of social dynamics and financial outcomes of Ponzi scheme diffusion in complex networks[J]. Physica A: Statistical Mechanics and its Applications, 2017.

[4] L. Zhao, Q. Wang, J. Cheng, et al. Rumor spreading model with consideration of forgetting mechanism: A case of online blogging LiveJournal[J]. Physica A: Statistical Mechanics and its Applications, 2011, 390(13): 2619-2625.

[5] Q. Wang, L. J. Zhao, R. B. Huang, et al. Interaction of media and disease dynamics and its impact on emerging infection management[J]. Discrete Continuous Dyn Syst Ser B, 2015, 20(1): 215-230.

[6] G. Ichinose, T. Kurisaku. Positive and negative effects of social impact on evolutionary vaccination game in networks [J]. Physica A: Statistical Mechanics and its Applications, 2017, 468: 84-90.

[7] M. N. Hajli. A study of the impact of social media on consumers [J]. International Journal of Market Research, 2014, 56(3): 387-404.

[8] S. E. Chang, A. Y. Liu, W. C. Shen. User trust in social networking services: A comparison of Facebook and LinkedIn [J]. Computers in Human Behavior, 2017, 69: 207-217.

[9] K. Schnitzler, N. Davies, F. Ross, et al. Using Twitter ${ }^{\mathrm{TM}}$ to drive research impact: a discussion of strategies, opportunities and challenges [J]. International journal of nursing studies, 2016, 59: 15-26.
[10] C. B. Zhang, Y. N. Li, B. Wu, et al. How WeChat can retain users: Roles of network externalities, social interaction ties, and perceived values in building continuance intention $[\mathrm{J}]$. Computers in Human Behavior, 2017, 69: 284-293.

[11] S. Mamonov, R. Benbunan-Fich. Exploring factors affecting social ecommerce service adoption: The case of Facebook Gifts [J]. International Journal of Information Management, 2017, 37(6): 590-600.

[12] C. Gan, F. Lee, Y. Li. Social media use, political affect, and participation among university students in urban China [J]. Telematics and Informatics, 2017.

[13] K. D. Goepel. Implementing the analytic hierarchy process as a standard method for multi-criteria decision making in corporate enterprises-a new AHP excel template with multiple inputs[C]//Proceedings of the international symposium on the analytic hierarchy process. 2013, 2013: $1-10$.

[14] M. A. Jenifer, M. K. Jha. Comparison of Analytic Hierarchy Process, Catastrophe and Entropy techniques for evaluating groundwater prospect of hard-rock aquifer systems [J]. Journal of Hydrology, 2017, 548: 605624.

[15] T. Chen, Y. Jin, X. Qiu, et al. A hybrid fuzzy evaluation method for safety assessment of food-waste feed based on entropy and the analytic hierarchy process methods [J]. Expert Systems with Applications, 2014, 41(16): 7328-7337.

[16] L. Li, F. Liu, C. Li. Customer satisfaction evaluation method for customized product development using Entropy weight and Analytic Hierarchy Process [J]. Computers \& Industrial Engineering, 2014, 77: 80-87.

[17] C. S. Gao, X. Rong, Y. Chen. Research on public opinion monitoring index-system in micro-blogging [J]. Journal of Intelligence, 2011, 30(9): 66-70. 